\title{
Anthropometric predictors for the risk of chronic disease in non-diabetic, non-hypertensive young Mexican women
}

\author{
Lynnette M Neufeld ${ }^{1, *}$, Jessica C Jones-Smith ${ }^{2}$, Raquel García ${ }^{1}$ and Lia CH Fernald ${ }^{2}$ \\ ${ }^{1}$ National Institute of Public Health - Mexico, División de Epidemiología de la Nutrición, Av. Universidad 655, \\ Sta. Ma. Ahuacatitlan, Cuernavaca, Morelos, 62508 México: ${ }^{2}$ School of Public Health, University of California - \\ Berkeley, Berkeley, CA, USA
}

Submitted 18 0ctober 2006: Accepted 13 March 2007: First published online 2 July 2007

\begin{abstract}
Objectives: To assess the ability of anthropometric measurements to identify young women at risk of developing diabetes, hypertension and heart disease in the future and to compare cut-off points for common anthropometric measures established with receiver-operating characteristic (ROC) curves with those reported in the literature.

Design: Cross-sectional study.

Subjects: Eight hundred and two young Mexican women living in semi-urban poverty.

Measurements/methods: The ability of anthropometric measures of fatness and fat distribution (body mass index (BMI), summed skinfold thickness (SST), waist circumference (WC), waist-to-hip ratio (WHR), conicity index (CI), abdominal volume index (AVI)) to predict risk of future disease (pre-diabetes: fasting blood glucose $100-126 \mathrm{mg} \mathrm{dl}^{-1}$; pre-hypertension: systolic blood pressure 120-139 $\mathrm{mmHg}$ and/or diastolic blood pressure 80-89 $\mathrm{mmHg}$; hypertriglyceridaemia: triglycerides $\geq 150 \mathrm{mg} \mathrm{dl}^{-1}$; or a combination of risk factors) was assessed using ROC curve analysis.

Results: Twenty-three of the 802 women who were interviewed had incomplete data and 50 (6.4\%) were eliminated from the analysis due to hypertension and/or diabetes. Mean age of the remaining 729 women was $29.6 \pm 5.4$ years and mean BMI was $27.7 \pm 4.5 \mathrm{~kg} \mathrm{~m}^{-2}$. There were no significant differences in the area under the ROC curve for BMI, WC, AVI or SST for any of the four outcomes. However, these indices performed significantly better than WHR and CI $(P<0.05)$. The BMI cut-off points that maximised sensitivity and specificity for the four outcomes were in the range of $27.7-28.4 \mathrm{~kg} \mathrm{~m}^{-2}$, and for WC were $89.3-91.2 \mathrm{~cm}$. To detect $90 \%$ of the cases of any metabolic alteration, the necessary BMI cut-off was $26.1 \mathrm{~kg} \mathrm{~m}^{-2}$. Younger women $(<25$ years) were at greater risk than older women for a given BMI increment $(P<0.05)$.

Conclusions: We found that BMI and WC cut-off points commonly used for the identification of risk of existing disease were also appropriate in this population for the identification of risk in the future among women without diabetes or hypertension. The early identification of at-risk individuals, prior to the onset of disease, is fundamental particularly in the context of a country with scarce resources that is rapidly undergoing nutrition transition.
\end{abstract}

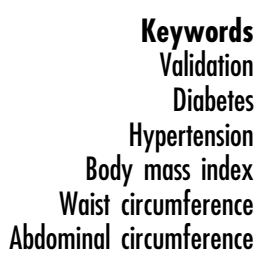

Keywords Validation Diabetes Hypertension Body mass index Abdominal circumference
In Mexico, as in many Latin American countries, overweight and obesity have now become major public health concerns ${ }^{1}$. According to the latest national nutrition surveys, the prevalence of overweight and obesity has increased dramatically over the last decade in Mexico with more than $60 \%$ of adult women currently overweight ${ }^{2}$. A recent survey among the rural poor showed that the prevalence of obesity for those living in extreme poverty is similar to national values ${ }^{3}$.
Compared with individuals in the recommended reference range for weight, those who are overweight or obese are at higher risk for dyslipidaemia ${ }^{4}$, hypertension ${ }^{5}$, insulin resistance ${ }^{6,7}$ and diabetes ${ }^{8}$, all of which substantially increase the risk for cardiovascular disease ${ }^{9,10}$. In Mexico, there is already a high prevalence of these chronic conditions, including diabetes ${ }^{11,12}$, hyperten$\operatorname{sion}^{13}$ and dyslipidaemia ${ }^{14}$. The cost of diabetes and other chronic diseases to the health system in a country such as 
Mexico is staggering ${ }^{15}$. Thus, it is critical to be able to target prevention efforts to those individuals who are at the greatest risk for developing these conditions. This is particularly important for public programmes where resources for intervention may be limited and efforts should be targeting those at highest risk.

In order to identify individuals at the greatest risk, researchers, practitioners and public health professionals have worked to identify the most appropriate simple anthropometric measures and the most appropriate cutoff points for easily assessed measurements such as body mass index (BMI) and waist circumference (WC) ${ }^{16,17}$. However, this task is made more challenging by the fact that negative health outcomes are seen at varying thresholds of commonly used anthropometric measurements depending on country of origin and ethnic group $^{18-20}$. Furthermore, several studies have suggested that body fat percentage at a given BMI varies by ethnic group $^{21-24}$. Although some studies have explored the need to establish appropriate cut-off points in diverse ethnic and regional populations ${ }^{19,25-30}$, most published studies continue to use standard recommended cut-off points to establish risk. Thus, the first objective of the study described here was to determine whether commonly used cut-off points are appropriate in a population of women living in poverty in semi-urban Mexico.

A common feature of studies that have looked at the predictive ability of various anthropometric measures is that they have been conducted in populations in which the prevalence of disease is already high ${ }^{19,25,26,29,30}$. In an effort to identify at-risk individuals before manifest disease develops, the American Diabetes Association (ADA) and the National Heart, Lung, and Blood Institute (NHLBI) have recently defined aggressive thresholds for diagnosing pre-diabetes and pre-hypertension ${ }^{31,32}$. Given the importance of early identification of chronic disease particularly in populations where health-care resources are scarce, it is critically important to know how well commonly used cut-off points for anthropometric measures can identify risk in young women. Thus, our second objective was to assess the ability of diverse anthropometric measurements to identify young women in the same population at risk of developing diabetes and hypertension using these newly established thresholds for pre-diabetes and prehypertension.

\section{Methods}

\section{Subjects}

The participants in the study had previously been part of a randomised controlled supplementation trial in a semiurban community in Morelos State, Mexico. Pregnant women were recruited through home visits conducted monthly from 1997 to 2000 and were provided with a daily multiple micronutrient or iron-only supplement from recruitment until delivery. Methods and results of that study are published elsewhere ${ }^{33,34}$ and will not be described here. From April to August 2005, all women who participated in the trial were re-visited and invited to participate in a follow-up study designed to document the association between diverse socio-economic, health and reproductive characteristics, and weight change over a 5-7-year period. Exclusion criteria for the follow-up study were current pregnancy or pregnancy within the past six months. The protocol for the follow-up study was approved by the Ethics, Biosecurity and Research Commissions of the National Institute of Public Health in Mexico and by the Center for the Protection of Human Subjects at the University of California, Berkeley. An informed consent declaration was signed by all women willing to participate after receiving complete information about the study objectives, procedures, risks and benefits. Women were also asked for permission that some of the information from the original study be used for the current analyses.

\section{Data collection and questionnaire}

Recruitment for the follow-up study was conducted in the woman's home and, if consent was obtained, an appointment was made to attend the study clinic in the community in the following one to three days. Appointments were made for the early morning and women were given clear instructions to attend in a fasting state (at least $8 \mathrm{~h}$ ). Each woman was interviewed by trained personnel to gather a brief medical history and a detailed description of socio-economic status, which included details of education, housing conditions, ethnicity, family size, occupation and possession of common assets (e.g. blender, television and refrigerator). Basic sociodemographic information was obtained from the original supplementation trial and updated as necessary.

Principal components analysis, a robust technique for reducing a large number of variables into one proxy measure, was used to summarise the asset variables into one estimate of socio-economic status (SES) ${ }^{35,36}$. The first principal component was retained under the assumption that the most common variation in the set of asset or housing variables would be a good proxy for household wealth ${ }^{37}$. Given that all participants in this study were from poor families, this index provides a relative comparison of families within the sample with no reference to the larger Mexican population. This type of index has been used to detect the influence of SES on diverse health outcomes in this ${ }^{34}$ and other ${ }^{38}$ populations.

\section{Blood sample}

A fasting venous blood sample was taken upon arrival at the study clinic; juice and a light snack were provided immediately after the sample was obtained. Fasting blood glucose (FBG), triglycerides and total cholesterol 
were assessed immediately with a portable glucometer (Accutrend GCT; Roche Diagnostics). Blood pressure was measured with a standard manual sphygmomanometer in sitting position.

Pre-diabetes was defined as $\mathrm{FBG}=100-125 \mathrm{mg} \mathrm{dl}^{-1}$ and diabetes as $\mathrm{FBG} \geq 126 \mathrm{mg} \mathrm{dl}^{-1}\left(\mathrm{ADA}^{31}\right)$. In accordance with the seventh report of the NHLBI's Joint National Committee on the Prevention, Detection, Evaluation and Treatment of High Blood Pressure ${ }^{32}$, systolic blood pressure $(\mathrm{SBP})=120-139 \mathrm{mmHg}$ and/or diastolic blood pressure $(\mathrm{DBP})=80-89 \mathrm{mmHg}$ was considered pre-hypertension, and $\mathrm{SBP} \geq 140 \mathrm{mmHg}$ and/or $\mathrm{DBP} \geq$ $90 \mathrm{mmHg}$ was considered hypertension. Given our interest in testing the ability of anthropometric indicators to identify individuals at risk of developing diabetes or hypertension in the future, all those diagnosed with current diabetes or hypertension based on FBG and blood pressure measurements were eliminated from the current analysis.

Triglyceride level $\geq 150 \mathrm{mg} \mathrm{dl}^{-1}$ was considered hypertriglyceridaemia. We also estimated a cluster of metabolic alterations using three of the four parameters suggested by the International Diabetes Federation (IDF) for metabolic syndrome ${ }^{39}$ - WC $>80 \mathrm{~cm}$ (suggested for ethnic Central and South American women) plus at least two of the following: (1) $\mathrm{SBP} \geq 130 \mathrm{mmHg}$ and/or DBP $\geq 80 \mathrm{mmHg}$; and/or (2) triglyceride level $\geq 150 \mathrm{mg} \mathrm{dl}^{-1}$; and/or (3) fasting plasma glucose $\geq 100 \mathrm{mg} \mathrm{dl}^{-1}$. We did not have high-density lipoproteins cholesterol measurements in this study to permit the assessment of metabolic syndrome as such.

\section{Antbropometric measurements and indices}

Weight, height, waist, hip and arm circumferences, and skinfold thicknesses were measured by a highly trained and standardised ${ }^{40}$ anthropometrist using standard procedures $^{41}$. Weight was measured in light clothing without shoes to the nearest $100 \mathrm{~g}$ on a digital scale (Tanita Mother-Baby scale, model 1582; Tanita Corp.). Height was measured in standard position with a portable stadiometer (Schorr Industries) and recorded to the nearest $\mathrm{mm}$. Waist, hip and mid-arm circumference measurements were taken to the nearest $\mathrm{mm}$ with a pliable measuring tape. WC was measured midway between the lowest rib and the iliac crest, with no garments in measurement. Hip circumference was measured in undergarments at the place of largest circumference around the buttocks. Mid-arm circumference was measured at the midpoint between the acromium and olecranon processes. Skinfold thickness measurements were taken at four sites - triceps, biceps, subscapular and suprailiac - using Lange skinfold callipers (Beta Technology). The measurements of weight, height, waist and hip circumferences were taken two times each and a third measurement was obtained if the difference between the two original measures surpassed preestablished limits. Skinfold thickness measurements were taken four times at each site. For all calculations and computations, we used the average of the repeated measurements.

BMI was calculated as $\mathrm{kg} \mathrm{m}^{-2}$ and waist-to-hip ratio (WHR) was calculated by dividing the waist circumference by the hip circumference. The four-site skinfold measurements were summed for an estimate of total body fat (SST) ${ }^{42}$. Abdominal volume index (AVI) was calculated as follows ${ }^{43}:\left[2 \mathrm{~cm} \times(\text { waist })^{2}+0.7 \mathrm{~cm} \times\right.$ (waist-hip) $\left.)^{2}\right] / 1000$; and conicity index (CI) as ${ }^{44}$ : waist/ $[0.109 \times$ sqrt(waist/height)]. Pre-obese and obesity were defined ${ }^{16}$ as $\mathrm{BMI}=25.0-29.9 \mathrm{~kg} \mathrm{~m}^{-2}$ and $\mathrm{BMI} \geq$ $30.0 \mathrm{~kg} \mathrm{~m}^{-2}$, respectively.

\section{Statistical analyses}

The ability of anthropometric measures to identify risk of disease was evaluated using four health outcomes: pre-hypertension, pre-diabetes, hypertriglyceridaemia and clustered metabolic alterations. Receiver-operating characteristic (ROC) curve analyses ${ }^{45,46}$ were used to examine the predictive capacity, sensitivity and specificity, and corresponding cut-off points of each of the six anthropometric measures (BMI, WC, AVI, WHR, SST, CI) on each of the four outcome measures. The overall performance of each anthropometric test for predicting each outcome was assessed by computing the area under the curve (AUC) ${ }^{46}$. For each outcome, the AUCs for all the anthropometric measures were compared and tested for significant differences. Sensitivity at each cut-off point was defined as the percentage of subjects who were classified as cases who truly had the condition. Likewise, specificity was defined as the percentage of subjects who did not have the condition and who were classified correctly at any given cut-off point. The cut-off point we report for each set of tests is that for which sensitivity and specificity are both maximised in the ROC curve analysis.

Based on a priori knowledge of the potential relationship between certain anthropometric measures and disease risk in diverse populations, we compared the predictive capabilities of BMI and WC for each metabolic outcome after stratifying by age and SES. For age, we divided the population into $<25,25-29.9$ and $\geq 30$ years (approximate tertiles of the current age). For SES, we categorised the population based on tertiles. The potential modifying effects of SES and age were examined for only BMI and WC for two reasons. First, BMI and WC demonstrated better predictive capacity than WHR and CI; second, they are much more commonly used and appropriate in the field than AVI or SST.

Finally, multiple linear and logistic regression analyses were used to quantify the effect of each incremental increase of BMI, WC and age on each metabolic outcome. 
The modifying effect of age on the relationship between BMI and the clustered metabolic alterations was tested as an interaction between age category (included in the model as two indicator variables) and BMI in a logistic regression model. We also tested whether short stature (defined as $<146$ or $<149 \mathrm{~cm}$ ) modified the relationship between BMI and metabolic alternations, due to some reports that BMI may perform more poorly as a predictor of risk of chronic disease in obese individuals with short stature $^{47}$. In addition, we tested whether the type of micronutrient supplement (iron-only or multiple micronutrients) taken during the pregnancy supplementation trial (4-6 years previously) was associated with our health outcomes or modified the relationship between anthropometric measurements and those health outcomes (tested as a statistical interaction between them). We also used linear regression to test whether micronutrient group was related to any of the six anthropometric indices.

Results were considered statistically significant if $P$-values were $<0.05$ and $<0.10$ for main effects and interactions, respectively ${ }^{48}$. All statistical analyses were completed using the STATA statistical package, version 9 (StataCorp.).

\section{Results}

A total of 802 women participated in the follow-up study; this sample represented $76 \%$ of those who had participated in the original trial. After excluding women with missing laboratory data, 779 women remained in the sample. Of these, 50 (6.4\%) women were eliminated from the current analysis due to current diagnosis as diabetic ( $n=35)$ or hypertensive $(n=11)$ or both $(n=4)$.

The mean age of the women included in the analysis was $29.6 \pm 5.4$ years. On average, the women had completed $7.1 \pm 3.2$ years of formal schooling. Mean BMI was $27.7 \pm 4.5 \mathrm{~kg} \mathrm{~m}^{-2} ; 313$ (42.9\%) women were classified as pre-obese and 206 (28.2\%) were classified as obese. Only seven $(1.0 \%)$ women in the sample were classified as underweight $\left(\mathrm{BMI}<18.5 \mathrm{~kg} \mathrm{~m}^{-2}\right)$. The prevalence of abdominal obesity $(52.5$ or $82.6 \%$, depending on classification used), pre-diabetes (25.6\%) and hypertriglyceridaemia (36.9\%) was high in the population (Table 1 ).

Based on the ROC curve analysis, there were no statistically significant differences in AUC between BMI, WC, AVI and SST for any of the four outcomes tested (pre-hypertension, pre-diabetes, hypertriglyceridaemia or clustered metabolic alterations) (Table 2). All four of these anthropometric indices, however, performed significantly better than WHR and CI for all outcomes. The cut-off points that maximised sensitivity and specificity varied by outcome for each anthropometric measure (Table 3). The BMI cut-off points that maximised sensitivity and specificity for our four outcomes ranged from 27.7 to $28.4 \mathrm{~kg} \mathrm{~m}^{-2}$ and for WC were 89.3 to $91.1 \mathrm{~cm}$.
Table 1 Prevalence of metabolic alterations in young women from semi-urban Mexico*

\begin{tabular}{lc}
\hline Condition & $\begin{array}{c}\text { Prevalence }(\%) \\
(n=729)\end{array}$ \\
\hline Abdominal adiposity $\dagger$ & \\
$\quad$ Abdominal obesity by IDF definition $(>80 \mathrm{~cm})$ & 82.6 \\
Abdominal obesity by NCEP definition $(>88 \mathrm{~cm})$ & 52.5 \\
Health outcomes & 25.6 \\
Pre-diabetes $\left(\mathrm{FBG}=100-125 \mathrm{mg} \mathrm{dl}^{-1}\right) \ddagger$ & 5.8 \\
Pre-hypertension $\left(\mathrm{SBP}=120-139 \mathrm{mmHg}^{-1}\right.$ and/ & \\
or DBP $=80-89 \mathrm{mmHg}) \S$ & 36.9 \\
Hypertriglyceridaemia $\left(>150 \mathrm{mg} \mathrm{dl}^{-1}\right)$ & 14.1 \\
Clustered metabolic alterations & \\
\hline
\end{tabular}

IDF - International Diabetes Federation; NCEP - National Cholesterol Education Program; FBG - fasting blood glucose; SBP - systolic blood pressure; DBP - diastolic blood pressure.

* Final sample after exclusion of individuals with missing laboratory data $(n=23)$, pre-existing diabetes $(n=35)$, hypertension $(n=11)$ or both $(n=4)$.

t Abdominal obesity classifications according to IDF and NCEP ${ }^{39}$

¥Pre-diabetes was defined according to the American Diabetes Association ${ }^{31}$.

§Pre-hypertension was defined according to the seventh report of the National Heart, Lung, and Blood Institute's Joint National Committee on Prevention, Detection, Evaluation and Treatment of High Blood Pressure $^{32}$.

- Defined using IDF definition for metabolic syndrome, excluding highdensity lipoprotein cholesterol criterion ${ }^{39}$.

Because WC $>80 \mathrm{~cm}$ is requisite for diagnosis of clustered metabolic alterations, the analysis of WC as a predictor of clustered metabolic alterations should be interpreted as the increase in risk associated with each increment in WC above $80 \mathrm{~cm}$.

According to our results, to detect $90 \%$ of the cases of clustered metabolic alteration in this population, the necessary BMI cut-off point would be $26.1 \mathrm{~kg} \mathrm{~m}^{-2}$ (results not shown). To detect $90 \%$ of the cases of pre-diabetes, everyone with BMI above $24.1 \mathrm{~kg} \mathrm{~m}^{-2}$ would need to be screened. All individuals with WC above $81.1 \mathrm{~cm}$ would need to be screened to detect $90 \%$ of pre-diabetes (results not shown).

When stratified by SES tertile, no differences were seen in the AUC of the ROC curve for either BMI or WC for any of the four outcomes tested (results not shown). However, when stratified by age, the overall predictive capacity, as measured by AUC, of both BMI and WC for clustered metabolic alterations varied significantly by age group (results not shown).

In the logistic regression analyses, BMI and WC were analysed in separate models due to high collinearity (Pearson correlation $=0.92$ ). In separate models, after adjusting for age, both BMI and WC were found to be significantly associated with each of the metabolic outcome variables (results not shown). Our comparative estimates of SES were not significantly associated with any of the outcomes.

Age modified the relationship between BMI and clustered metabolic alterations. A given increment in BMI for women $<25$ years of age was associated with a greater increment in risk of clustered metabolic alterations than a 
Table 2 Area under the receiver-operating characteristic curve (AUC) for each anthropometric index and each metabolic alteration in young Mexican women without diabetes or hypertension

\begin{tabular}{|c|c|c|c|}
\hline Outcome variable & $\begin{array}{l}\text { Anthropometric } \\
\text { measure }\end{array}$ & $A \cup C^{*}$ & $\begin{array}{c}\text { Maximised sensitivity \& } \\
\text { specificity }(\%)\end{array}$ \\
\hline \multirow[t]{6}{*}{ Pre-hypertensiont } & BMI & $0.68(0.59-0.77)^{\mathrm{a}}$ & 60 \\
\hline & WC & $0.70(0.61-0.79)^{a}$ & 61 \\
\hline & $A V I \|$ & $0.70(0.61-0.79)^{a}$ & 62 \\
\hline & SST & $0.71(0.63-0.79)^{a}$ & 67 \\
\hline & WHR & $0.65(0.56-0.74)^{b}$ & 59 \\
\hline & $\mathrm{Cl}^{\star *}$ & $0.68(0.59-0.76)^{b}$ & 62 \\
\hline \multirow[t]{6}{*}{ Pre-diabetes $\ddagger$} & $\mathrm{BMI}$ & $0.65(0.61-0.69)^{a}$ & 61 \\
\hline & WC & $0.64(0.60-0.69)^{a}$ & 61 \\
\hline & AVI & $0.64(0.60-0.69)^{a}$ & 60 \\
\hline & SST & $0.64(0.59-0.69)^{\mathrm{a}}$ & 61 \\
\hline & WHR & $0.57(0.53-0.62)^{b}$ & 53 \\
\hline & $\mathrm{Cl}$ & $0.57(0.52-0.62)^{b}$ & 56 \\
\hline \multirow[t]{6}{*}{ Hypertriglyceridaemia§ } & BMI & $0.70(0.66-0.74)^{a}$ & 65 \\
\hline & WC & $0.69(0.66-0.73)^{a}$ & 64 \\
\hline & AVI & $0.69(0.66-0.73)^{a}$ & 64 \\
\hline & SST & $0.68(0.64-0.72)^{a}$ & 64 \\
\hline & WHR & $0.63(0.59-0.67)^{b}$ & 60 \\
\hline & $\mathrm{Cl}$ & $0.63(0.59-0.67)^{b}$ & 60 \\
\hline \multirow[t]{6}{*}{ Clustered metabolic alterations $\uparrow$} & BMI & $0.72(0.67-0.76)^{a}$ & 64 \\
\hline & WC & $0.71(0.66-0.76)^{a}$ & 65 \\
\hline & AVI & $0.71(0.66-0.76)^{a}$ & 65 \\
\hline & SST & $0.71(0.66-0.76)^{a}$ & 67 \\
\hline & WHR & $0.62(0.57-0.68)^{b}$ & 59 \\
\hline & $\mathrm{Cl}$ & $0.62(0.56-0.68)^{b}$ & 58 \\
\hline
\end{tabular}

$\mathrm{BMI}$ - body mass index; WC - waist circumference; AVI - abdominal volume index; SST, summed skinfold thickness; WHR - waist-to-hip ratio; $\mathrm{Cl}$ - conicity index.

*Within each metabolic outcome, all AUCs marked a are equal to each other as are all AUCs marked b. However, the AUCs marked a are significantly different from those marked $\mathrm{b}(P<0.05)$.

tPre-hypertension was defined in accordance with the recommendations of the seventh report of the National Heart, Lung, and Blood Institute's Joint National Committee on Prevention, Detection, Evaluation and Treatment of High Blood Pressure $^{32}$ : systolic blood pressure (SBP) between 120 and $139 \mathrm{mmHg}$ and/or diastolic blood pressure (DBP) between 80 and $89 \mathrm{mmHg}$.

$\ddagger$ Pre-diabetes was defined as fasting blood glucose between 100 and $125 \mathrm{mg} \mathrm{dl}^{-1}$.

$\S$ Hypertriglyceridaemia defined as triglyceride level $\geq 150 \mathrm{mg} \mathrm{dl}^{-1}$.

- Clustered metabolic alterations was calculated using three of the four parameters suggested by the International Diabetes Federation for metabolic syndrome ${ }^{39}-W C>80 \mathrm{~cm}$ (suggested for ethnic Central and South American women) plus at least two of the following: (1) SBP $\geq 130 \mathrm{mmHg}$ and/or DBP $\geq 80 \mathrm{mmHg}$; and/or (2) triglyceride level $\geq 150 \mathrm{mg} \mathrm{dl}^{-1}$; and/or (3) fasting plasma glucose $\geq 100 \mathrm{mg} \mathrm{dl}^{-1}$.

$\|$ AVI calculated as proposed by Guerrero-Romero and Rodriguez-Moran ${ }^{43}$ : $\left[2 \mathrm{~cm} \times(\text { waist })^{2}+0.7 \mathrm{~cm} \times(\text { waist }-\mathrm{hip})^{2}\right] /$ 1000.

${ }^{\star \star} \mathrm{Cl}$ calculated according to the formula developed by Valdez et al. ${ }^{44}$ : waist/[0.109 $\times$ sqrt(waist/height)].

Table 3 Cut-off points to maximise sensitivity and specificity for metabolic alterations in young Mexican women developed based on receiver-operating characteristic curve analysis.

Cut-off point for maximised sensitivity and specificity

\begin{tabular}{lcccc} 
Anthropometric measurement & Pre-hypertension* & Pre-diabetest & Hypertriglyceridaemiał & Clustered metabolic alterations \\
\hline BMI $\left(\mathrm{kg} \mathrm{m}^{-2}\right)$ & 28.2 & 27.8 & 27.7 & 28.4 \\
WC $(\mathrm{cm})$ & 91.1 & 89.8 & 89.3 & 91.2 \\
AVI & 16.7 & 16.1 & 16.0 & 16.7 \\
SST $(\mathrm{mm})$ & 103.6 & 97.3 & 96.3 & 101.3 \\
WHR & 0.89 & 0.88 & 0.88 & 0.89 \\
CIII & 1287.1 & 1274.3 & 1273.5 & 1279.5
\end{tabular}

BMI - body mass index; WC - waist circumference; AVI - abdominal volume index; SST - summed skinfold thickness; WHR - waist-to-hip ratio; CI - conicity index.

*Pre-hypertension was defined in accordance with the recommendations of the seventh report of the National Heart, Lung, and Blood Institute's Joint National Committee on Prevention, Detection, Evaluation and Treatment of High Blood Pressure ${ }^{32}$ : systolic blood pressure (SBP) between 120 and 139 mmHg and/or diastolic blood pressure (DBP) between 80 and $89 \mathrm{mmHg}$.

+Pre-diabetes was defined as fasting blood glucose between 100 and $125 \mathrm{mg} \mathrm{dl}^{-1}$ $\ddagger$ Hypertriglyceridaemia defined as triglyceride level $\geq 150 \mathrm{mg} \mathrm{dl}^{-1}$.

$\S$ Clustered metabolic alterations was calculated using three of the four parameters suggested by the International Diabetes Federation for metabolic syndrome $^{39}-W C>80 \mathrm{~cm}$ (suggested for ethnic Central and South American women) plus at least two of the following: (1) SBP $\geq 130 \mathrm{mmHg}$ and/or DBP $\geq 80 \mathrm{mmHg}$; and/or (2) triglyceride level $\geq 150 \mathrm{mg} \mathrm{dl}^{-1}$; and/or (3) fasting plasma glucose $\geq 100 \mathrm{mg} \mathrm{dl}^{-1}$.

- AVI calculated as proposed by Guerrero-Romero and Rodriguez-Moran ${ }^{33}:\left[2 \mathrm{~cm} \times(\text { waist })^{2}+0.7 \mathrm{~cm} \times(\text { waist-hip })^{2}\right] / 1000$.

$\| \mathrm{Cl}$ calculated according to the formula developed by Valdez et al. ${ }^{44}$ : waist/[0.109 $\times$ sqrt(waist/height)]. 


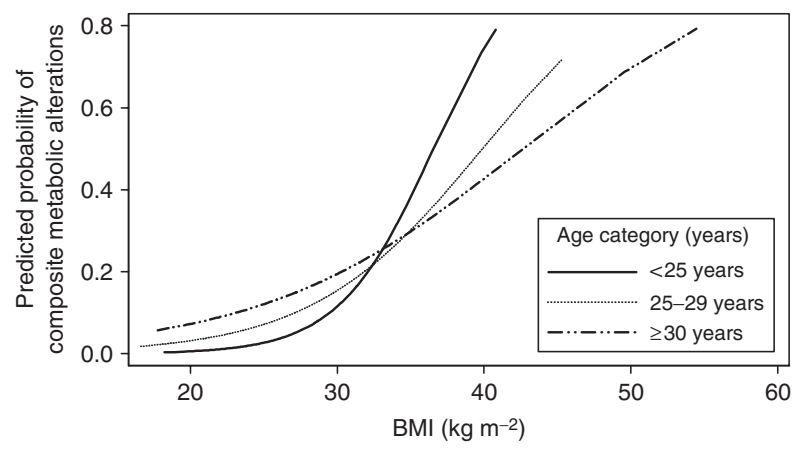

Fig. 1 Association between body mass index (BMI) and probability of clustered metabolic alterations by age category

similar increment among women aged 25 years or above ( $P=0.04$ for interaction) (Fig. 1). Similarly, age modified the relationship between WC and clustered metabolic alterations ( $P=0.07$ for interaction); however, as mentioned above, the interpretation of this applies only to increases in $\mathrm{WC}$ above $80 \mathrm{~cm}$ since $\mathrm{WC} \geq 80 \mathrm{~cm}$ is requisite for diagnosis of clustered metabolic alterations. Height did not significantly modify the relationship between BMI and metabolic alterations, nor did we find any modifying effect of age on the relationship between WC and FBG, blood pressure or fasting triglycerides.

The type of micronutrient supplement consumed during pregnancy (multiple micronutrient or iron-only) was not significantly associated with any of the anthropometric indices or health outcomes, nor did it modify the relationship between anthropometric indices and health outcomes.

\section{Discussion}

In this study we found that BMI and WC were the best, field-appropriate indicators to identify future risk for the development of hypertension, diabetes and cardiovascular disease in a sample of young women from semiurban Mexico living in poverty. It is noteworthy that, although few women were eliminated from the analysis due to pre-existing diabetes or hypertension, over $70 \%$ of these women were pre-obese or obese and the mean BMI was high $\left(27.7 \mathrm{~kg} \mathrm{~m}^{-2}\right)$. This prevalence is higher than that reported in previous studies conducted in Mexico $^{26,47,49}$ and is likely to reflect a continuation of the rapid increase in obesity reported previously in Mexico ${ }^{2}$.

Recent studies have produced differing conclusions about which anthropometric measure has the best predictive capacity for detecting disease risk. Contrary to the analysis by Sanchez-Castillo et al. ${ }^{49}$, who reported that WC demonstrated a significantly better predictive capacity for detecting cases of diabetes mellitus and hypertension, we found no statistically significant difference in the predictive ability of BMI and WC, estimated using area under the ROC curve. In fact, the AUCs in our analysis for
BMI and WC were not statistically significantly different from those for SST and AVI. In situations when resources are sufficient, the estimation of SST and AVI may provide additional information for research or clinical practice about fat vs. lean mass, but we consider these measures to have little practical application in the context of field studies or assessments at small public health centres.

The BMI cut-off points that maximised sensitivity and specificity for our four outcomes ranged from 27.7 to $28.4 \mathrm{~kg} \mathrm{~m}^{-2}$. These cut-off points are very similar to those reported in a national sample of older women in Mexico for the diagnosis of existing diabetes $\left(28.0 \mathrm{~kg} \mathrm{~m}^{-2}\right)$ or hypertension $\left(27.8 \mathrm{~kg} \mathrm{~m}^{-2}\right)^{49}$ and are slightly higher than those found in a smaller sample of older hospital workers to diagnose existing diabetes $\left(25.4 \mathrm{~kg} \mathrm{~m}^{-2}\right)$ or hypertension $\left(26.6 \mathrm{~kg} \mathrm{~m}^{-2}\right)^{26}$. In the nationally representative sample of the Mexican population ( $n=26647$ women, mean age $37.3 \pm 12.9$ years, mean BMI $27.6 \pm 5.6 \mathrm{~kg} \mathrm{~m}^{-2}$ ) there was a much higher prevalence of hypertension (25.6\%) and diabetes (7.2\%). In the sample of older hospital workers ( $n=5939$ women, $n=2426$ men, mean age $39.1 \pm 14.3$ years, mean BMI $25.5 \pm 4.5 \mathrm{~kg} \mathrm{~m}^{-2}$ ) the prevalence was lower for diabetes (5.8\%) and hypertension (17.9\%). A number of characteristics of the study participants may in part explain these differences, including socio-economic status, prevalence of smoking or alcohol consumption, health status of the population, and diagnostic methodologies. Unfortunately, the data as presented in the studies do not permit a quantification of the extent to which these factors may have influenced the results.

The unique contribution of our study is the documentation that anthropometric measurements and cut-off points similar to those used to identify existing disease are effective in identifying elevated risk in a sample without pre-existing disease, in which the average age of the participants is 10 years younger than those previously sampled in Mexico. Another important contribution of our study is that we have analysed data from a group of low-income women living in semi-urban areas. The relationship between anthropometric measurements and risk has been under-researched, despite the rapid increase in overweight, obesity and chronic disease among populations living in poverty in Mexico and other regions of Latin America ${ }^{1}$.

The BMI cut-off point necessary to detect $90 \%$ of the cases of pre-diabetes in our sample $\left(24.1 \mathrm{~kg} \mathrm{~m}^{-2}\right)$ is slightly higher than the equivalent cut-off point found in the nationally representative sample to detect existing diabetes $\left(23.0 \mathrm{~kg} \mathrm{~m}^{-2}\right)^{49}$, while our cut-off point for WC is lower $(81.1 \mathrm{vs} .83 .0 \mathrm{~cm})$. It is likely that the cut-off points differed because of the use of diverging diagnostic criteria for fasting and non-fasting samples. One limitation of the national study was the lack of information on the time between last food intake and blood sample collection, necessitating the diagnosis of diabetes based on casual blood glucose criterion ( $>200 \mathrm{mg} \mathrm{dl}^{-1}$ ), which may have introduced a bias in the results if a large number of 
individuals were in a fasting state in spite of the fact that non-fasting criteria were used. Clearly, future research is needed to clarify the influence of these methodological details on the differences in BMI cut-off points presented in diverse studies and settings.

There is considerable debate in the literature as to whether anthropometric measures may perform differently for the prediction of disease risk in diverse ethnic and geographic populations. Two studies in populations of Asian origin have reported WHR to have superior predictive capacity than WC only, while similar studies in the USA have reported WC to be superior to $\mathrm{WHR}^{20,28,29,50}$. It has been suggested that variance in optimal BMI for predicting disease risk is at least partially due to differing body composition, ethnicity and/or geographic region of ori$\operatorname{gin}^{21-24}$. In other words, for a given BMI, the percentage and distribution of body fat may differ by ethnicity and/or geographic region of origin.

Few studies have looked specifically at the body composition per BMI unit of persons of Hispanic origin. One study compared the body composition of Americans of Hispanic, African and European origin and found that, at a BMI of less than $30 \mathrm{~kg} \mathrm{~m}^{-2}$, Hispanic Americans tended to have a higher percentage of body fat than did European Americans and African Americans ${ }^{22}$. This finding may partially explain a trend towards lower optimal cut-off points for predicting concurrent disease and lower cut-off points for increased risk of disease in Mexicans living in Mexico ${ }^{26,49}$ as compared with European Americans. The IDF has recommended the use of ethnic-specific cut-off points for the diagnosis of abdominal adiposity, but not BMI, and acknowledges the current lack of data specific to Central and South America. In these populations, the IDF recommends the use of cutoff points established for Asian populations, i.e. WC $\geq$ $80 \mathrm{~cm}$ for females. If this definition of abdominal adiposity is used, $82.6 \%$ of our study population would be considered abdominally obese.

In our study, a given increment in BMI in the youngest subgroup of the study population has more negative implications for future disease risk than a similar increment among older individuals. A similar relationship after stratifying by age has been seen in other studies ${ }^{49,51-53}$ which may be because BMI is a less sensitive measure for total body fat as age increases ${ }^{54}$. This finding emphasises the importance of prevention from a young age.

In Mexico, as in many middle-income and even lowincome countries, the prevalence of obesity has increased dramatically in recent years and, with it, the burden of related preventable chronic disease. It is clear that aggressive actions are needed at the national level in Mexico to reverse this trend and prevent the dramatic costs that this will have on individuals and society in the future. As part of this strategy, health systems should identify atrisk individuals and provide intensified interventions for them; particularly where resources are scare and more population-based interventions may not be sustainable. The identification of at-risk individuals at a relatively young age, prior to the onset of disease, is fundamental. In this study, we found that BMI and WC cut-off points similar to those used for the identification of individuals with disease are the most field-appropriate means to identify individuals with elevated risk to develop diabetes and/or hypertension. Given the similarity in their predictive ability, the choice of which to use in a specific context could depend on resources and the ease of taking height and weight vs. waist circumference measures. The identification of individuals at risk before overt disease presents itself through the use of appropriate anthropometric indicators and cutoff points will allow medical and public health practitioners to channel those at highest risk into programmes. This strategy will be critical to reduce the burden of obesity and chronic disease currently faced by the Mexican healthcare system.

\section{Acknowledgements}

Sources of funding: The work was funded by the Berkeley Consortium on Population Health (R21 MH70950, Principal Investigator Tom Boyce).

Conflict of interest declaration: The authors have no financial or other conflicts of interest.

Authorship responsibilities: L.M.N. and L.C.H.F. conceived the study, obtained funding, developed the field methodology and provided guidance and supervision throughtout. R.G. assisted with design of the field methods and provided supervision and data quality control in the field. J.C.J.-S. conducted the statistical analysis and assisted with writing the manuscript. L.M.N. wrote the manuscript. All authors read and approved the final version of the manuscript.

Acknowledgements: We thank the Berkeley Consortium on Population Health for funding this study. Thanks also to the families who participated in the research, and the research assistants who collected the data.

\section{References}

1 Uauy R, Albala C, Kain J. Obesity trends in Latin America: transitioning from under- to overweight. Journal of Nutrition 2001; 131(3): 893S-9S.

2 Rivera JA, Sepúlveda-Amor J. Conclusions from the Mexican National Survey 1999: translating results into nutrition policy. Salud Pública de México 2003; 45(Suppl. 4): S565-75.

3 Fernald LC, Gutierrez JP, Neufeld LM, Mietus-Snyder M, Olaiz GO, Bertozzi SM, et al. High prevalence of obesity among the poor in Mexico. JAMA: Journal of the American Medical Association 2004; 291(21): 2544-5.

4 Hubert HB, Feinleib M, McNamara PM, Castelli WP. Obesity as an independent risk factor for cardiovascular disease: a 26-year follow-up of participants in the Framingham Heart Study. Circulation 1983; 67(5): 968-77. 
5 Thompson D, Edelsberg J, Colditz GA, Bird AP, Oster G. Lifetime health and economic consequences of obesity. Archives of Internal Medicine 1999; 159(18): 2177-83.

6 Eckel RH, Grundy SM, Zimmet PZ. The metabolic syndrome. Lancet 2005; 365(9468): 1415-28.

$7 \mathrm{Hu}$ G, Qiao Q, Tuomilehto J, Balkau B, Borch-Johnsen K, Pyorala K. Prevalence of the metabolic syndrome and its relation to all-cause and cardiovascular mortality in nondiabetic European men and women. Archives of Internal Medicine 2004; 164(10): 1066-76.

8 Colditz GA, Willett WC, Rotnitzky A, Manson JE. Weight gain as a risk factor for clinical diabetes mellitus in women. Annals of Internal Medicine 1995; 122(7): 481-6.

9 Poirier P, Giles TD, Bray GA, Hong Y, Stern JS, Pi-Sunyer FX, et al. Obesity and cardiovascular disease: pathophysiology, evaluation, and effect of weight loss: an update of the 1997 American Heart Association scientific statement on obesity and heart disease from the obesity committee of the council on nutrition, physical activity, and metabolism. Circulation 2006; 113(6): 898-918.

10 Manson JE, Willett WC, Stampfer MJ, Colditz GA, Hunter DJ, Hankinson SE, et al. Body weight and mortality among women. New England Journal of Medicine 1995; 333(11): $677-85$.

11 Stern MP, Gonzalez C, Mitchell BD, Villalpando E, Haffner SM, Hazuda HP. Genetic and environmental determinants of type II diabetes in Mexico city and San Antonio. Diabetes 1992; 41(4): 484-92.

12 Aguilar-Salinas CA, Vazquez-Chavez C, Gamboa-Marrufo R, Garcia-Soto N, de Jesus Rios-Gonzalez J, Holguin R, et al. Obesity, diabetes, hypertension, and tobacco consumption in an urban adult Mexican population. Archives of Medical Research 2001; 32(5): 446-53.

13 Gonzalez Villalpando C, Stern MP, Arredondo Perez B, Valdez R, Mitchell B, Haffner S. Prevalence and detection of hypertension in Mexico. Archives of Medical Research 1994; 25(3): 347-53.

14 Gonzalez Villalpando C, Stern MP, Arredondo Perez B, Martinez Diaz S, Haffner S. Undiagnosed hypercholesterolemia: a serious health challenge. The Mexico City Diabetes Study. Archives of Medical Research 1996; 27(1): 19-23.

15 Arredondo A, Zúñiga A. Economic consequences of epidemiological changes in diabetes in middle-income countries. The Mexican case. Diabetes Care 2004; 27(1): 104-9.

16 World Health Organization (WHO). Physical Status: The Use and Interpretation of Anthropometry. Report of a WHO Expert Committee. Technical Report Series No. 854. Geneva: WHO, 1995.

17 National Institutes of Health. Clinical guidelines on the identification, evaluation, and treatment of overweight and obesity in adults - the evidence report. Obesity Research 1998; 6(Suppl. 2): 51S-209S.

18 WHO Expert Committee. Appropriate body-mass index for Asian populations and its implications for policy and intervention strategies. Lancet 2004; 363(9403): 157-63.

19 Razak F, Anand S, Vuksan V, Davis B, Jacobs R, Teo KK, et al. SHARE Investigators, Ethnic differences in the relationships between obesity and glucose-metabolic abnormalities: a cross-sectional population-based study. International Journal of Obesity 2005; 29(6): 656-67.

20 Ko GT, Tang J, Chan JC, Sung R, Wu MM, Wai HP, et al. Lower BMI cut-off value to define obesity in Hong Kong Chinese: an analysis based on body fat assessment by bioelectrical impedance. British Journal of Nutrition 2001; 85(2): 239-42.

21 Deurenberg P, Deurenberg-Yap M, Guricci S. Asians are different from Caucasians and from each other in their body mass index/body fat per cent relationship. Obesity Reviews 2002; 3(3): 141-6.
22 Fernandez JR, Heo M, Heymsfield SB, Pierson Jr RN, Pi-Sunyer FX, Wang ZM, et al. Is percentage body fat differentially related to body mass index in Hispanic Americans, African Americans, and European Americans? American Journal of Clinical Nutrition 2003; 77(1): 71-5.

23 Kagawa M, Kerr D, Uchida H, Binns CW. Differences in the relationship between BMI and percentage body fat between Japanese and Australian-Caucasian young men. British Journal of Nutrition 2006; 95(5): 1002-7.

24 Craig P, Halavatau V, Comino E, Caterson I. Differences in body composition between Tongans and Australians: time to rethink the healthy weight ranges? International Journal of Obesity and Related Metabolic Disorders 2001; 25(12): 1806-14.

25 Okosun IS, Liao Y, Rotimi CN, Choi S, Cooper RS. Predictive values of waist circumference for dyslipidemia, type 2 diabetes and hypertension in overweight white, black, and Hispanic American adults. Journal of Clinical Epidemiology 2000; 53(4): 401-8.

26 Berber A, Gomez-Santos R, Fanghanel G, Sanchez-Reyes L. Anthropometric indexes in the prediction of type 2 diabetes mellitus, hypertension and dyslipidaemia in a Mexican population. International Journal of Obesity and Related Metabolic Disorders 2001; 25(12): 1794-9.

27 Ito H, Nakasuga K, Ohshima A, Maruyama T, Kaji Y, Harada $\mathrm{M}$, et al. Detection of cardiovascular risk factors by indices of obesity obtained from anthropometry and dual-energy $\mathrm{X}$-ray absorptiometry in Japanese individuals. International Journal of Obesity and Related Metabolic Disorders 2003; 27(2): 232-7.

28 Lin WY, Lee LT, Chen CY, Lo H, Hsia HH, Liu IL, et al. Optimal cut-off values for obesity: using simple anthropometric indices to predict cardiovascular risk factors in Taiwan. International Journal of Obesity and Related Metabolic Disorders 2002; 26(9): 1232-8.

29 Zhu S, Heymsfield SB, Toyoshima H, Wang Z, Pietrobelli A, Heshka S. Race-ethnicity-specific waist circumference cutoffs for identifying cardiovascular disease risk factors. American Journal of Clinical Nutrition 2005; 81(2): 409-15.

30 Esmaillzadeh A, Mirmiran P, Azizi F. Comparative evaluation of anthropometric measures to predict cardiovascular risk factors in Tehranian adult women. Public Health Nutrition 2006; 9(1): 61-9.

31 American Diabetes Association. Diagnosis and classification of diabetes mellitus. Diabetes Care 2006; 29(Suppl. 1): S43-8.

32 Chobanian AV, Bakris GL, Black HR, Cushman WC, Green LA, Izzo Jr JL, et al. National Heart, Lung, and Blood Institute Joint National Committee on Prevention, Detection, Evaluation, and Treatment of High Blood Pressure, National High Blood Pressure Education Program Coordinating Committee. The seventh report of the Joint National Committee on prevention, detection, evaluation, and treatment of high blood pressure: the JNC 7 report. JAMA: Journal of the American Medical Association 2003; 289(19): 2560-72.

33 Ramakrishnan U, Gonzalez-Cossio T, Neufeld LM, Rivera J, Martorell R. Effect of prenatal multiple micronutrient supplements on maternal weight and skinfold changes: a randomized double-blind clinical trial in Mexico. Food and Nutrition Bulletin 2005; 26(3): 273-80.

34 Ramakrishnan U, Gonzalez-Cossio T, Neufeld LM, Rivera J, Martorell R. Multiple micronutrient supplementation during pregnancy does not lead to greater infant birth size than does iron-only supplementation: a randomized controlled trial in a semirural community in Mexico. American Journal of Clinical Nutrition 2003; 77(3): 720-5.

35 Montgomery MR, Gragnolati M, Burke KA, Paredes E. Measuring living standards with proxy variables. Demography 2000; 37(2): 155-74. 
36 Falkingham J, Namazie C. Measuring Health and Poverty: A Review of Approaches to Identifying the Poor. London: Department for International Development, Health Systems Resource Centre, 2002.

37 Filmer D, Pritchett LH. Estimating wealth effects without expenditure data - or tears: an application to educational enrollments in states of India. Demography 2001; 38(1): 115-32.

38 Ruel MT, Rivera J, Habicht JP, Martorell R. Differential response to early nutritional supplementation: long-term effects on height at adolescence. International Journal of Epidemiology 1995; 24(2): 404-12.

39 Alberti KG, Zimmet P, Shaw J, IDF Epidemiology Task Force Consensus Group. The metabolic syndrome - a new worldwide definition. Lancet 2005; 366(9491): 1059-62.

40 Habicht JP. [Standardization of quantitative epidemiological methods in the field]. Boletin de la Oficina Sanitaria Panamericana 1974; 76(5): 375-84.

41 Lohman TG, Roche AF, Martorell R. Anthropometric Standardization Reference Manual. Champaign, IL: Human Kinetics Books, 1989.

42 Durnin JVGV, Womersley J. Body fat assessed from total body density and its estimation from skinfold thickness: measurements on 481 men and women aged from 16 to 72 years. British Journal of Nutrition 1974; 32(1): 77-97.

43 Guerrero-Romero F, Rodriguez-Moran M. Abdominal volume index. An anthropometry-based index for estimation of obesity is strongly related to impaired glucose tolerance and type 2 diabetes mellitus. Archives of Medical Research 2003; 34(5): 428-32.

44 Valdez R, Seidell JC, Ahn YI, Weiss KM. A new index of abdominal adiposity as an indicator of risk for cardiovascular disease. A cross-population study. International Journal of Obesity and Related Metabolic Disorders 1993; 17(2): 77-82.

45 Brownie C, Habicht JP, Cogill B. Comparing indicators of health or nutritional status. American Journal of Epidemiology 1986; 124(6): 1031-44.
46 Van der Schouw YT, Verbeek AL, Ruijs JH. ROC curves for the initial assessment of new diagnostic tests. Family Practitioner 1992; 9(4): 506-11.

47 Lara-Esqueda A, Aguilar-Salinas CA, Velazquez-Monroy O, Gomez-Perez FJ, Rosas-Peralta M, Mehta R, et al. The body mass index is a less-sensitive tool for detecting cases with obesity-associated co-morbidities in short stature subjects. International Journal of Obesity and Related Metabolic Disorders 2004; 28(11): 1443-50.

48 Cohen J, Cohen P, West SG, Aiken LS. Applied Multiple Regression/Correlation Analyses for the Behavioral Sciences, 3rd ed. Mahwah, NJ: Lawrence Erlbaum Associates, 2003.

49 Sanchez-Castillo CP, Velazquez-Monroy O, Berber A, LaraEsqueda A, Tapia-Conyer R, James WP, Encuesta Nacional de Salud (ENSA) 2000 Working Group. Anthropometric cutoff points for predicting chronic diseases in the Mexican National Health Survey 2000. Obesity Research 2003; 11(3): 442-51

50 Zhu S, Wang Z, Heshka S, Heo M, Faith MS, Heymsfield SB. Waist circumference and obesity-associated risk factors among whites in the third National Health and Nutrition Examination Survey: clinical action thresholds. American Journal of Clinical Nutrition 2002; 76(4): 743-9.

51 Park HS, Song YM, Cho SI. Obesity has a greater impact on cardiovascular mortality in younger men than in older men among non-smoking Koreans. International Journal of Epidemiology 2006; 35(1): 181-7.

52 Stevens J, Cai J, Pamuk ER, Williamson DF, Thun MJ, Wood JL. The effect of age on the association between body-mass index and mortality. New England Journal of Medicine 1998; 338(1): 1-7.

53 Flegal KM, Graubard BI, Williamson DF, Gail MH. Excess deaths associated with underweight, overweight, and obesity. JAMA: Journal of the American Medical Association 2005; 293(15): 1861-7.

54 Flint AJ, Rimm EB. Commentary: Obesity and cardiovascular disease risk among the young and old - is BMI the wrong benchmark? International Journal of Epidemiology 2006; 35(1): 187-9. 